\title{
Acquired von Willebrand's syndrome with IgM inhibitor against von Willebrand's factor
}

\author{
M. GOUAULT-HEILMANN, M. D. DUMONT, L. INTRATOR, C. CHENAL, AND \\ J. L. LEJONC
}

From the Service Central d'Hématologie-Immunologie, Hôpital Henri Mondor et Département d'Hématologie Biologique de la Faculté de Médecine de Créteil, 94010 Creteil, France

SUMMARY This report describes a patient without evident underlying disease, in whom an acquired von Willebrand's syndrome was discovered before surgery. Coagulation abnormalities included a borderline bleeding time, a low retention of platelets on glass beads, decreased levels of factor VIII procoagulant activity ( VIII $_{\mathrm{AHF}}$ ), factor VIII-related antigen (VIII $\mathrm{Ag}_{\mathrm{B}}$ ), and ristocetin-induced agglutination cofactor $\left(\mathrm{VIII}_{\mathrm{VWF}}\right)$. After cryoprecipitate infusion the patient did not have the expected rise and there was no secondary increment in VIII $_{\mathrm{AHF}}$. The patient was treated with prednisone for three weeks without significant improvement in the laboratory findings. Spontaneous resolution was observed long after this therapy. The haemostatic abnormalities were attributable to the presence of an inhibitor directed against VIII $\mathrm{VwF}_{\mathrm{vw}}$. This inhibitor was found in the IgM fraction. Its autoimmune nature is probable although we failed to demonstrate any inhibitory effect of Fab obtained from the patient's purified IgM. Despite the lack of inhibitory effect against VIII AHF $_{\text {and }}$ VIII $_{\mathrm{Ag}}$, the low levels of all three activities of the factor VIII complex could be explained by the short half-life of immune complexes between factor VIII and the inhibitor.

Classical von Willebrand's disease is a congenital bleeding disorder with an autosomal dominant inheritance characterised by a long bleeding time, decreased platelet retention on glass beads, decreased factor VIII procoagulant activity, decreased factor VIII antigen, and decreased ristocetin-induced agglutination cofactor. This pattern defines typical von Willebrand's disease although various genetic variants have been reported (Hoyer, 1976). In recent years some patients with an acquired form of the disease have been described. Most of them occur during the course of autoimmune diseases, and in rare cases autoantibodies have been demonstrated. The present report describes a patient without evident underlying disease in whom an acquired von Willebrand's syndrome was discovered before surgery and attributed to an antibody that selectively destroyed the VIIIvwF activity.

\section{Case report}

A 72 year-old man was first investigated in February 1978 because of a prolonged partial thromboplastin time, which was discovered before a total

Received for publication 27 March 1979 hip replacement. He had had no bleeding symptoms until three months previously, when he developed a massive haematoma on the thigh after surgery for inguinal hernia. There was no bleeding problem in the family, and coagulation studies of the patient's sister and son were normal. The patient had no spontaneous bleeding at the onset of our investigations. Physical examination was normal. Morphological and immunological studies did not reveal any autoimmune or lymphoproliferative disorder (antinuclear factor was absent; Coombs and RoseWaaler tests were negative; $\mathrm{C} 3$ and $\mathrm{C} 4$ levels were normal; cryoglobulins and circulating immune complexes were not detected; bone marrow aspirate and biopsy showed no lymphocytic infiltration). The total serum protein content was $64 \mathrm{~g} / 1$ with a $2 \mathrm{~g} / \mathrm{l}$ peak in the $\gamma$ globulin fraction. Immunoelectrophoresis showed a monoclonal IgG of the lambda type. The polyclonal IgA, IgM, and IgG globulin levels were normal. Proteinuria was 70 $\mathrm{mg} / 24 \mathrm{~h}$, and immunoelectrophoresis of the concentrated urine showed diffuse proteinuria with two monoclonal light chains, one of the lambda type and one of the kappa type. The haemostatic abnormalities and the late onset of the disorder suggested an acquired von Willebrand's disease (see below). 
The clinical and biological manifestations did not respond to three weeks' treatment with prednisone. At the end of treatment the patient developed a massive melaena, but gastrointestinal investigations (endoscopic and radiological) were normal. This haemorrhagic manifestation resolved spontaneously although there was no change in the laboratory findings.

\section{Material and methods}

ROUTINE COAGULATION STUDIES

Bleeding time was performed by the method of Ivy modified by Borchgrevink (1960).

In-vivo platelet retention was measured during the Ivy bleeding time by the Borchgrevink (1960) technique.

Glass-bead platelet retention was measured according to a modified technique of Hellem (1970) using commercial packed glass bead columns with a blood flow of $5 \mathrm{ml} / 30 \mathrm{~s}$ (Mascia Brunelli, Milan).

Prothrombin time, activated partial thromboplastin time, thrombin time, fibrinogen, clot retraction, residual serum prothrombin assay, and factors II, V, and VII $+\mathrm{X}$ assays (one-stage method) were performed according to Josso and Prou-Wartelle (1972).

Factor VIII and factor IX procoagulant activities were measured by a one-stage procedure using haemophilic plasmas as substrate.

Factor VIII $_{\mathrm{Ag}}$ was measured by electroimmunodiffusion according to Laurell (1966) using a specific rabbit antihuman factor VIII antiserum (Behringwerke). VIII $_{\text {Ag }}$ was also studied by crossed immunoelectrophoresis on cryoprecipitates from normal and patient's plasmas.

\section{RISTOCETIN-INDUCED AGGLUTINATION}

COFACTOR (VIIIVWF)

This was measured according to Weiss et al. (1973) using fresh washed normal platelets and a final ristocetin concentration of $1.5 \mathrm{mg} / \mathrm{ml}$.

INHIBITORY EFFECT OF PATIENT'S PLASMA Equal volumes of normal pooled citrated plasma and patient's plasma heated to $56^{\circ} \mathrm{C}$ for 1 hour were incubated for 2 hours at $37^{\circ} \mathrm{C}$. After centrifugation the mixture was tested for residual factor VIII $_{\mathrm{AHF}}$, VIII $_{\text {Ag }}$, and VIIIvwF.

\section{CRYOPRECIPITATE INFUSION STUDIES}

Freeze-dried cryoprecipitate (from the Centre National de Transfusion Sanguine) corresponding to $40 \mathrm{U}$ VIII $_{\mathrm{AHF}}, 133 \mathrm{U}$ VIII $_{\mathrm{Ag}}$, and $33 \mathrm{U}$ VIIIvwr per kg of body weight was infused. Blood samples were withdrawn at 0,30 minutes, 1 hour,
$2,3,6,24$, and 48 hours, and tested for $\mathrm{VIII}_{\mathrm{AHF}}$, VIII $_{\text {Ag, and VIIIvwF. }}$

IMMUNOLOGICAL STUDIES

Serum was kept frozen at $-20^{\circ} \mathrm{C}$. The lipoproteins were precipitated by dextran sulphate and euglobulins by boric acid. Fractionation of the serum was carried out using DEAE cellulose in $0.005 \mathrm{~m}$ sodium phosphate buffer $\mathrm{pH} 6 \cdot 5$. The ascending half of the exclusion peak contained the monoclonal lambda IgG and the polyclonal IgG globulins. Fractionation of the serum was also carried out using gel filtration on Sephadex G 200 in $0.2 \mathrm{M}$ tris- $\mathrm{HCl}, 1 \mathrm{M} \mathrm{NaCl}$ buffer $\mathrm{pH}$ 8. The ascending half of the exclusion peak containing only the IgM globulins was kept. This fraction gave a single precipitation line in double immunodiffusion against anti human normal serum. Papain digestion of the polyclonal IgM was performed using the technique described by Mihaesco and Seligmann (1968). The 24-hour digests were submitted to gel filtration on Sephadex G 200 columns. The elution peaks corresponding to $\mathrm{Fc}$ $(\mu)$ and Fab $(\mu)$ were concentrated and tested by immunoelectrophoresis and Ouchterlony techniques using rabbit antisera (CDTS Rouen, and Sebia).

Purified immunoglobulins and their fragments from patient's and normal sera were tested for inhibitory activity against VIII $_{A H F}$, VIII $_{A g}$, and VIIIvwF using mixtures of equal volumes of immunoglobulins or their fragments and normal plasma. These purified fractions did not induce ristocetin platelet aggregation in the absence of normal plasma.

\section{Results}

ROUTINE COAGULATION DATA

The results are summarised in the Table. Both invivo and in-vitro platelet retention were greatly reduced, contrasting with a borderline prolongation of bleeding time. The activated partial thromboplastin time was prolonged and $\mathrm{VIII}_{\mathbf{A H F}}, \mathrm{VIII}_{\mathbf{A g}}$, and VIIIvwf were diminished. Platelet count, prothrombin time, fibrinogen, and factors II, V, $\mathrm{VII}+\mathrm{X}$ levels were within the normal range. These data agree well with those usually observed in von Willebrand's disease. Coagulation data from the patient's sister and son were normal.

Table Coagulation and platelet function tests

\begin{tabular}{|c|c|c|}
\hline & Patient & Control \\
\hline 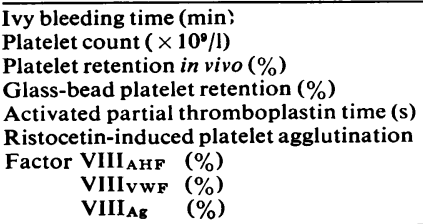 & $\begin{array}{r}11 \\
227 \\
3 \\
0 \\
65 \\
\text { None } \\
17 \\
<10 \\
9\end{array}$ & $\begin{array}{r}<10 \\
200-400 \\
20-40 \\
>\quad 7311 \\
45-55 \\
- \\
50-200 \\
50-200 \\
50-200\end{array}$ \\
\hline
\end{tabular}


CRYOPRECIPITATE INFUSION STUDIES

In an attempt to demonstrate an inhibitory activity in vivo, we studied the patient's response after cryoprecipitate infusion (Fig. 1). The immediate

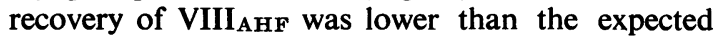
value (at least $100 \%$ ), and no secondary rise of

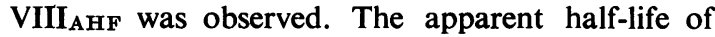

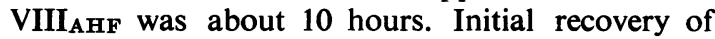
VIII $_{\mathbf{A g}}$ and VIIIvwF was lower than expected but the rate of their disappearance appeared normal.

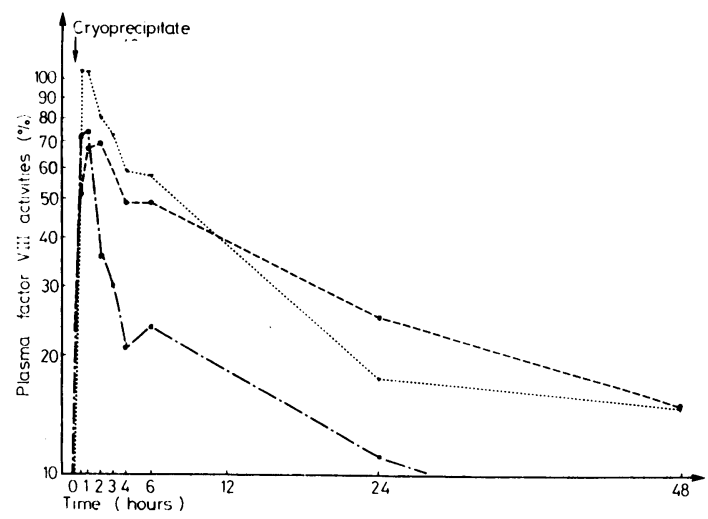

Fig. 1 Plasma factor VIII activities after cryoprecipitate infusion: - - - VIII $I_{A H F} ; \ldots . V I I I_{A g} ;-.--V I I I_{V W F}$ $\begin{array}{lrl}\text { cryoprecitate: } & 40 \mathrm{U} / \mathrm{kg} & V I I_{A H F} \\ & 133 \mathrm{U} / \mathrm{kg} & V I I_{A g} \\ & 33 \mathrm{U} / \mathrm{kg} & V I I I_{V W F} .\end{array}$

INHIBITORY EFFECT OF PATIENT'S PLASMA No inhibitory activity against VIIIVHF was found in vitro even after 2 hours' incubation at $37^{\circ} \mathrm{C}$. An attempt to dissociate antigen-antibody complexes by heating the patient's plasma at $56^{\circ} \mathrm{C}$ did not reveal any inhibitory effect. Patient's plasma did not interfere with the precipitation of normal VIII $_{\mathrm{Ag}}$ by heterologous antibodies. It was difficult to decide on any inhibitory activity against VIIIvwF: in the mixture of normal and patient's plasmas the initial velocity is not reduced but the maximum change in light transmission is slightly decreased compared with normal plasma and buffer (Fig 2a).

INHIBITORY EFFECT OF PATIENT'S PURIFIED IMMUNOGLOBULIN FRACTIONS (Fig. 2b, c)

Fractions of patient's serum containing pure IgG (including the monoclonal protein) or $\operatorname{IgA} \operatorname{did}$ not inhibit either ristocetin-induced agglutination of normal washed platelets or VIII AHF. Patient's IgM, however, had an inhibitory activity against VIIIvwF but not against VIII $_{A H F}$ or VIII $_{\text {Ag. }}$. When the Fc $(0.0625$ to $1 \mathrm{mg} / \mathrm{ml}$ final $)$ and $\mathrm{Fab}$ $(0.075$ to $1.125 \mathrm{mg} / \mathrm{ml}$ final) fragments were purified from the patient's IgM, however, neither could be shown to retain any inhibitory activity against factor VIII.

CROSSED IMMUNOELECTROPHORESIS STUDIES Crossed immunoelectrophoresis was performed on normal and patient's cryoprecipitate instead of plasma, because of the very low level of patient's

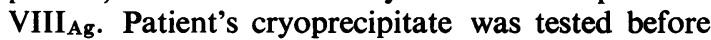
and after the infusion of factor VIII concentrate and during prednisone therapy. No abnormality of migration was found.

EVOLUTION DURING AND AFTER TREATMENT The patient was given prednisone, $1-2 \mathrm{mg} / \mathrm{kg} /$ day for three weeks. The results of laboratory findings are shown in Figure 3. No significant change in any of the factor VIII complex activities occurred during the course of this treatment. About one month after cessation of treatment factor VIII activities started to rise in, first, VIII $_{A H F}$, then VIII $_{A g}$, and, finally, VIIIvwr. Purified IgM from the July sample still had an inhibitory effect against VIIIvwF.

\section{Discussion}

The patient reported here had the laboratory features of von Willebrand's syndrome (Hoyer, 1976). Its acquired nature was suspected because of the late onset of the disease and the absence of a familial bleeding history. An abnormal response to cryoprecipitate infusion suggested the presence of an inhibitor of the factor VIII complex, which was demonstrated by in-vitro studies. This inhibitor was selectively directed against VIIIvwr. Its probable autoimmune nature was supported by the presence of the inhibitory activity in the immunoglobulin fraction, its association with other immunoglobulin abnormalities, and the spontaneous recovery.

Since 1968 , some 16 cases of acquired von Willebrand's disease have been reported. Some cases occurred in association with systemic lupus erythematosus (Simone et al., 1968; Ingram et al., 1971; Poole-Wilson, 1972; Ingram et al., 1973; Leone et al., 1974; Gazengel et al., 1978) while others were described with lymphoproliferative disorders (Handin et al., 1976; Wautier et al., 1976; Joist et al., 1978) and a few with monoclonal immunoglobulins without evidence of multiple myeloma (Ingram et al., 1971; Mant et al., 1973; Meyer et al., 1974; Rosborough and Swaim, 1978). One case occurred after pesticide ingestion (Veltkamp et al., 1970). In the case reported here, the acquired von Willebrand's syndrome was associated with a monoclonal gammopathy without evident lymphoproliferative or autoimmune disease. 

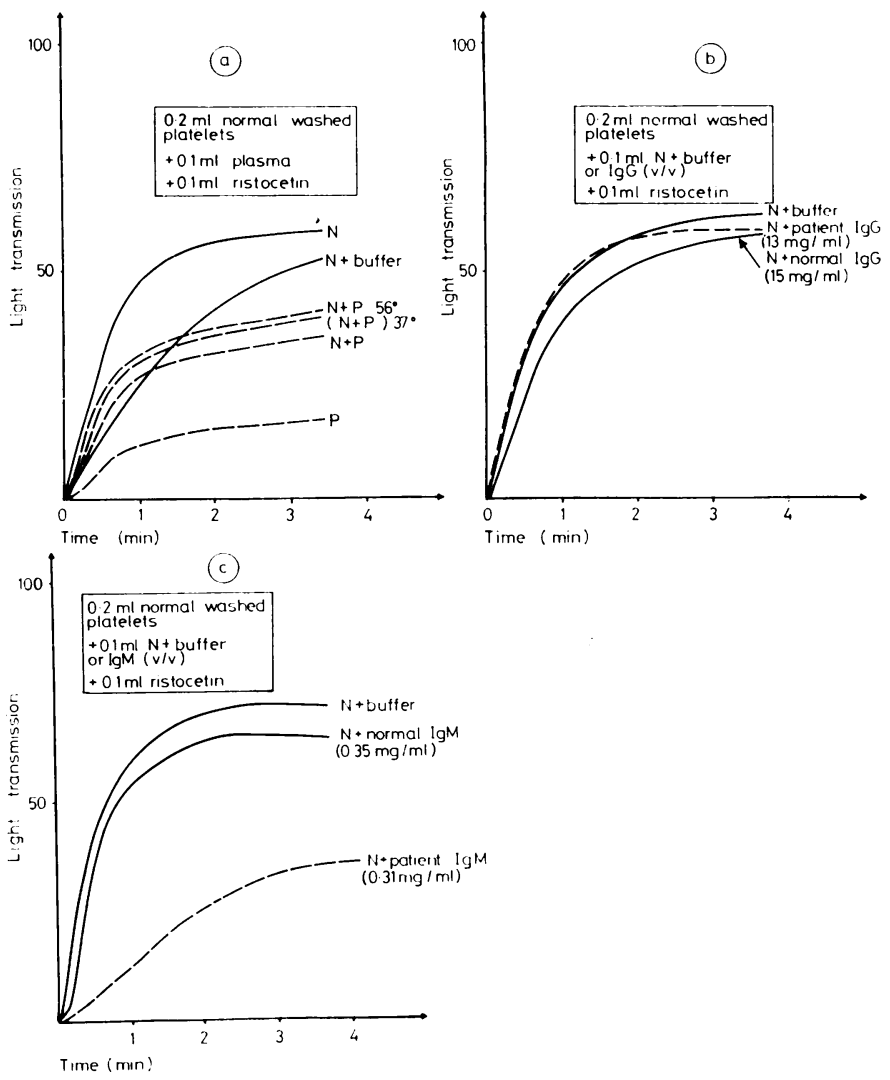

An abnormal response to factor VIII concentrate infusion was described in most of the cases (Mant et al., 1973; Handin et al., 1976; Stableforth et al., 1976; Rosborough and Swaim, 1978; Gazengel et al., 1978). Recovery of injected factor VIII $_{\text {AHF }}$ was generally poor and without the sustained rise usually observed in patients with congenital von Willebrand's disease (Chediak et al., 1977). Of the cases in which in-vitro evidence of an inhibitor was found, three had inhibitory activity against ristocetin cofactor alone (Leone et al., 1974; Handin et al., 1976; Wautier et al., 1976), while in one case inhibitor was also directed against factor VIII $\mathrm{AHF}$ (Stableforth $e t$ al., 1976) and in an-

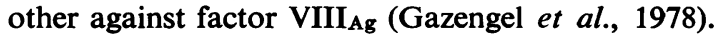
In those cases in which immunoglobulins were purified, the inhibitor was found either in the IgG fraction (Handin et al., 1976; Gazengel et al., 1978) or in the IgA fraction (Wautier et al., 1976) but never in the IgM fraction. In none of the reported cases has papain digestion of the immunoglobulins been performed in order to demonstrate the precise autoantibody nature of the inhibitor.
Fig. 2 Ristocetin-induced agglutination of normal washed platelets: (a) plasmas; (b) purified IgG; (c) purified IgM. $N=$ normal plasma; $\boldsymbol{P}=$ patient's plasma.

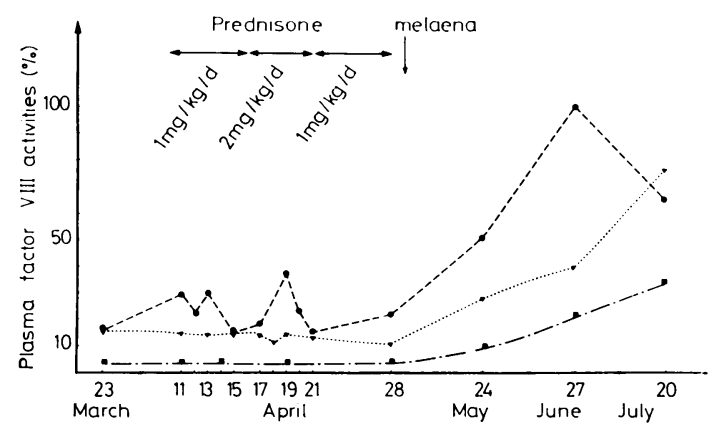

Fig. 3 Evolution of plasma factor VIII activities: - - VIII $I_{A H F} ; . . . V I I I_{A g} ;$ - - - VIIIVWF.

Our patient had the same characteristics as most of the cases reviewed: the main distinguishing features are the IgM nature of the inhibitor and the spontaneous remission. We did not find any inhibitory activity in Fab fragments obtained from the patient's total purified IgM, perhaps because only very few 
anti VIIIvwF molecules were present in the test system used. An alternative explanation might be that papain fragmentation of IgM was not suitable for the demonstration of this type of antibody but that pepsin digestion (leading to $F\left(a b^{\prime}\right) 2$ fragments) would have been more appropriate. The Fc fragments of IgM had no inhibitory activity against ristocetin-induced platelet agglutination, as was demonstrated for Fc fragments of IgG in the same protein concentration range (Moore et al., 1978). Despite the absence of inhibitory activity in Fab fragments other findings strongly suggest that the inhibitor is autoimmune in nature.

Much evidence suggests that VIIIvwF activity is closely related to the binding sites of xenogeneic antibodies. The inhibitory activity of our patient's antibody could be demonstrated only against VIIIvwF and not against other attributes of the factor VIII complex. It is interesting that, in contrast to the case reported by Gazengel et al. (1978), the binding of the IgM inhibitor to the VWF site did not affect the recognition of the molecule by xenogeneic antibodies. The concomitant reduction in VIII $_{A H F}$ and VIII $_{A g}$ in patient's plasma could be explained by the short half-life of immune complexes formed between the VIIIvwF antigenic site and the autoantibody, resulting in the removal of the whole factor VIII complex.

We thank Dr A. Artigout, who referred this patient to us, and Drs P. Brochard, and A. Schaeffer for their clinical assistance. We are indebted to Professor R. M. Hardisty for improving the manuscript and to Dr M. Levent and the technicians for their help.

\section{References}

Borchgrevink, C. F. (1960). A method for measuring platelet adhesiveness in vivo. Acta Medica Scandinavica, 168, 157-164.

Chediak, J. R., Telfer, M. C., and Green, D. (1977). Platelet function and immunologic parameters in von Willebrand's disease following cryoprecipitate and factor VIII concentrate infusion. American Journal of Medicine, 62, 369-376.

Gazengel, C., Prieur, A. M., Jacques, C., Buriot, D., Nedellec, J., and Josso, F. (1978). Antibody induced von Willebrand's syndrome: Inhibition of VIII vw F and VIII $_{\mathrm{AGN}}$ with sparing of $\mathrm{VIII}_{\mathrm{AHF}}$ by the autoantibody. American Journal of Hematology, 5, 355-363.

Handin, R. I., Martin, V., and Moloney, W. C. (1976). Antibody-induced von Willebrand's disease: a newly defined inhibitor syndrome. Blood, 48, 393-405.

Hellem, A. J. (1970). Platelet adhesiveness in von Willebrand's disease. Scandinavian Journal of Haematology, 7, 374-382.

Hoyer, L. W. (1976). Von Willebrand's disease. Progress in Hemostasis and Thrombosis, 3, 231-287.
Ingram, G. I. C., Kingston, P. J., Leslie, J., and Bowie, E. J. (1971). Four cases of acquired von Willebrand's syndrome. British Journal of Haematology, 21, 189-199.

Ingram, G. I. C., Prentice, C. R. M., Forbes, C. D., and Leslie, J. (1973). Low factor VIII-like antigen in acquired von Willebrand's syndrome and response to treatment. British Journal of Haematology, 25, 137-140.

Joist, J. H., Cowan, J. F., and Zimmerman, T. S. (1978). Acquired von Willebrand's disease. Evidence for a quantitative and qualitative factor VIII disorder. New England Journal of Medicine, 298, 988-991.

Josso, F., and Prou-Wartelle, O. (1972). In Techniques en Hématologie, edited by D. Alagille, F. Josso, J. M. Fine and J. Colombani, Flammarion, Paris.

Laurell, C. B. (1966). Quantitative estimation of proteins by electrophoresis in agarose gel containing antibodies. Analytical Biochemistry, 15, 45-52.

Leone, G., Pola, P., Guerrera, G., and Bizzi, B. (1974). Sindrome di von Willebrand acquisita in corso di malattia disreattiva. Haematologica, 59, 212-220.

Mant, M. J., Hirsh, J., Gauldie, J., Bienenstock, J., Pineo, G. F., and Luke, K. H. (1973). Von Willebrand's syndrome presenting as an acquired bleeding disorder in association with a monoclonal gammopathy. Blood, 42, 429-436.

Meyer, D., Jenkins, C. S. P., Dreyfus, M. D., Fressinaud, E., and Larrieu, M. J. (1974). Willebrand factor and ristocetin. II. Relationship between Willebrand factor, Willebrand antigen and factor-VIII activity. British Journal of Haematology, 28, 579-599.

Mihaesco, C., and Seligmann, M. (1968). Papain digestion fragments of human IgM globulins. Journal of Experimental Medicine, 127, 431-453.

Moore, A., Ross, G. D., and Nachman, R. L. (1978). Interaction of platelet membrane receptors with von Willebrand factor, ristocetin and the Fc region of immunoglobulin G. Journal of Clinical Investigation, 62, 1053-1060.

Poole-Wilson, P. A. (1972). Acquired von Willebrand's syndrome and systemic lupus erythematosus. Proceedings of the Royal Society of Medicine, 65, 561-562.

Rosborough, T. K., and Swaim, W. R. (1978). Acquired von Willebrand's disease, platelet-release defect and angiodysplasia. American Journal of Medicine, 65, 96-100.

Simone, J. V., Cornet, J. A., and Abildgaard, C. F. (1968). Acquired von Willebrand's syndrome in systemic lupus erythematosus. Blood, 31, 806-812.

Stableforth, P., Tamagnini, G. L., and Dormandy, K. M. (1976). Acquired von Willebrand syndrome with inhibitors both to factor VIII clotting activity and ristocetin-induced platelet aggregation. British Journal of Haematology, 33, 565-573.

Veltkamp, J. J., Stevens, P., Plas, M. V. D., and Loeliger E. A. (1970). Production site of bleeding factor. Thrombosis et Diathesis Haemorrhagica, 23, 412.

Wautier, J. L., Levy-Toledano, S., and Caen, J. P. (1976). Acquired von Willebrand's syndrome and thrombopathy in a patient with chronic lymphocytic leukaemia. Scandinavian Journal of Haematology, 16, 128-134.

Weiss, H. J., Hoyer, L. W., Rickles, F. R., Varna, A., and Rogers, J. (1973). Quantitative assay of a plasma 
factor deficient in von Willebrand's disease that is Requests for reprints to: Dr M. Gouault-Heilmann, necessary for platelet aggregation. Journal of Clinical Service Central d'Hématologie-Immunologie, Hôpital Investigation, 52, 2708-2716. Henri Mondor, 94010 Creteil, France. 